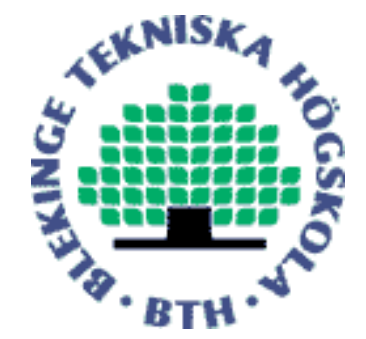

Copyright (C) 2014 IEEE.

Citation for the published paper:

Optimization of switched-beam arrays for communication systems

Edson R. Schlosser, Roger L. Farias, Marcos V. T. Heckler, Renato Machado

Wireless Communications Systems (ISWCS)

2014 Barcelona

This material is posted here with permission of the IEEE. Such permission of the IEEE does not in any way imply IEEE endorsement of any of BTH's products or services Internal or personal use of this material is permitted. However, permission to reprint/republish this material for advertising or promotional purposes or for creating new collective works for resale or redistribution must be obtained from the IEEE by sending a blank email message to pubs-permissions@ieee.org.

By choosing to view this document, you agree to all provisions of the copyright laws protecting it. 


\section{Optimization of Switched-Beam Arrays for Communication Systems}

\author{
Edson R. Schlosser, Roger L. Farias, \\ Marcos V. T. Heckler \\ Universidade Federal do Pampa, UNIPAMPA \\ Alegrete, Brazil \\ \{edsonschlosser, marcos.heckler\}@unipampa.edu.br \\ rogerlorenzoni@gmail.com
}

\author{
Renato Machado \\ Blekinge Institute of Technology \\ Karlskrona, Sweden \\ Federal University of Santa Maria \\ Santa Maria, RS, Brazil \\ renatomachado@ieee.org
}

\begin{abstract}
This paper presents the application of optimization methods for the synthesis of a linear array for communication systems. By means of suitably beam switching, the array should provide coverage of a given angular area in azimuth and should allow controlling the sidelobe level simultaneously. For this purpose, two optimization methods have been used to calculate the excitation coefficient for each desired beam. The synthesis technique is demonstrated for arrays composed of isotropic and microstrip elements. By comparing the results obtained for both arrays, the need of consideration of the array element pattern during the synthesis process is demonstrated.
\end{abstract}

Keywordsbeamforming; antenna arrays; genetic algorithm;

microstrip sequential

antennas; programming.

\section{INTRODUCTION}

The application of optimization methods has allowed the development of complex antenna architectures, especially for the synthesis of microstrip arrays or other printed antenna geometries [1]. Microstrip technology is used in several applications, such as global positioning system (GPS) [2], mobile communication systems [3] and among others. In many of these applications, beam steering capability is desired, whereby the control of radiation pattern parameters such as half-power beamwidth and sidelobe level is necessary in order to reduce radiated power into unwanted directions. These restrictions are realized by pattern synthesis, which consists of determining the amplitudes and phases of the currents that should be impressed at the terminals of the different elements that compose the antenna array.

The excitation coefficients can be calculated with several approaches. Some classical techniques, such as Fourier transform and the Woodward-Lawson method [4], may not produce adequate results when applied for beamshaping of complicated patterns, unless a large number of array elements are considered with few elements to compose the array. However, the consideration of large arrays impacts on the complexity for construction. By employing the classical synthesis techniques for a small number of elements, the obtained patterns may have considerable sidelobe levels. The Dolph-Tschebyscheff method is well known for sidelobe level control, but this technique is directly applicable only for arrays

This work has been partially supported by the Brazilian National Council for Scientific and Technological Development $(\mathrm{CNPq})$ under contract no. 475325/2011-7. composed of isotropic elements. Additionally, the sidelobe level control tends to fail if the main beam is steered off from the boresight.

This paper presents an alternative approach for the synthesis of antenna arrays with an efficient and robust technique based on two optimization methods: genetic algorithm (GA) [5] and sequential quadratic programming (SQP) [6]. In [7], the combination of these methods has demonstrated to provide accurate results in short computation time. The next section presents the antenna array theory used during the optimization process. Then, the combination of GA and SQP methods is discussed, whereby GA is used to start the global search of the desired set of excitation coefficients for the array and SQP is applied for the final refinement of the solution. A high-gain microstrip element designed to operate in the frequency allocated for wireless communication systems is described. The radiation pattern of this antenna has been used to assess the performance of a switched-beam linear antenna array. Finally, the synthesis of isotropic and microstrip antennas is realized and compared.

\section{THEORETICAL BACKGROUND}

In this work, the mathematical formulation is derived for an array with linear elements arranged along the $z$-direction, since the array factor for this case is only dependent on the $\theta$ coordinate of the spherical coordinate system. The geometry is sketched in Fig. 1. The mathematical formulation can be easily adapted to array elements along other orientations. The total electric field radiated by a linear array composed of $N$ elements is given by

$$
\vec{E}_{\text {array }}=\sum_{i=1}^{N} \vec{E}_{i} e^{j k_{0} z_{i} \cos \theta}
$$

where $\vec{E}_{i}$ is the radiated electric field by the $i$-th element of the array, $z_{i}=(i-1) . d, d$ is the uniform spacing between adjacent array elements, and $k_{0}$ is the propagation constant in free space. 
The term $\vec{E}_{i}$ can be expanded to

$$
\vec{E}_{i}=I_{i} \frac{e^{-j \cdot k \cdot r}}{r} \vec{e}_{i}(\theta, \phi),
$$

where $I_{i}$ is a complex value representing the current impressed (excitation coefficient) at the terminals of the $i$-th antenna, $r$ is the radial distance to the origin of the coordinate, and

$$
\vec{e}_{i}(\theta, \phi)=e_{i \theta}(\theta, \phi) \hat{\theta}+e_{i \phi}(\theta, \phi) \hat{\phi}
$$

is the term containing the angular dependence of the single element radiation pattern used to compose the array. In many studies in the literature, the authors usually consider isotropic elements, i.e. $\left|\vec{e}_{i}(\theta, \phi)\right|=1$. However, the real antenna radiation pattern does not have isotropic characteristics and is a function of the radiator geometry. For example, in [8], the pattern of the single element is considered during the optimization process. In (1) and (2), the summation of $I_{i} e^{j k_{0} z_{i} \cos \theta}$ is known as the array factor $(A F)$, which is a complex and dimensionless quantity that depends on the position of each element in the array and on the excitation current. By specifying a given pattern, the synthesis process is used to determine the complex $I_{i}$ values (amplitude and phase).

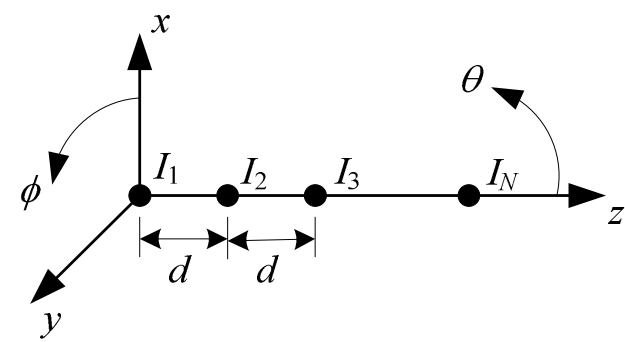

Fig. 1 - Geometry of a linear array of $N$ isotropic antennas along $z$.

\section{OPTIMIZATION METHODS FOR ARRAY SYNTHESIS}

In this paper, two optimization methods have been employed to find the excitation coefficients of linear arrays. Initially, GA was used to search for a set of coefficients that synthesizes the specified pattern; then, SQP was applied to refine the solution. The SQP is always started with the best individual obtained after running the GA.

The GA is based on individuals in the population that are treated as potential solutions to the problem. An initial population is generated randomly and suffers crossover and mutation over generations. With the evolution of the individuals, the GA shall find better results to solve the problem.

The fitness of each individual is given based on the evaluation of its chromosome as a cost function. The cost function used in this study for both methods is based on the error, calculated by

$$
g(\theta)=F(\theta)-\left|\vec{E}_{\text {array }}(\theta)\right|, \theta \in\left[0^{\circ}, 180^{\circ}\right]
$$

where $\vec{E}_{\text {array }}(\theta)$ is the obtained radiated electric field when the linear antenna array is excited by a set of currents, $F(\theta)$ is the desired pattern, $g(\theta)$ corresponds to the difference between of the radiation patterns for a given angle $\theta \in$ $\left[0^{\circ}, 180^{\circ}\right]$.

The fitness of each individual is a measure of the solution quality, i.e. how close the specification the solution is. Mathematically, the fitness is defined here as

$$
\text { fitness }=\left[\frac{1}{L} \sum_{i=1}^{L}\left|g\left(\theta_{i}\right)\right|^{2}\right]^{\frac{1}{2}}
$$

where $L$ is the number of samples in the angular region under optimization. Thus, the chromosome that is represented by the lowest fitness value is considered to be the best adapted individual to solve the proposed optimization problem. In terms of radiated field, one can state that the individual that presents the best fitness will produce the closest radiation pattern to the specification.

For evaluation purposes, each set of excitation coefficients, represented by a chromosome, described as a vector $I$, with the following representation

$$
I=\left[\left|I_{1}\right| \angle \phi_{1}\left|I_{2}\right| \angle \phi_{2}\left|I_{3}\right| \angle \phi_{3} . .\left|I_{N}\right| \angle \phi_{N}\right]
$$

where $\left|I_{i}\right|$ corresponds to the amplitude and $\phi_{i}$ the phase of $i$-th excitation current

The desired pattern follows the shape sketched in Fig. 2, where the main beam should point to $\theta_{m}$. The regions of the sidelobes are defined in the ranges of $\left[\theta_{a}, \theta_{b}\right]$ and $\left[\theta_{d}, \theta_{e}\right]$, whereby a maximum allowed value is set and should be equal or less than $S L L$. For a switched-beam architecture, the mask will be applied for different values of $\theta_{m}$ and by keeping the same $S L L$ value for all steering directions.

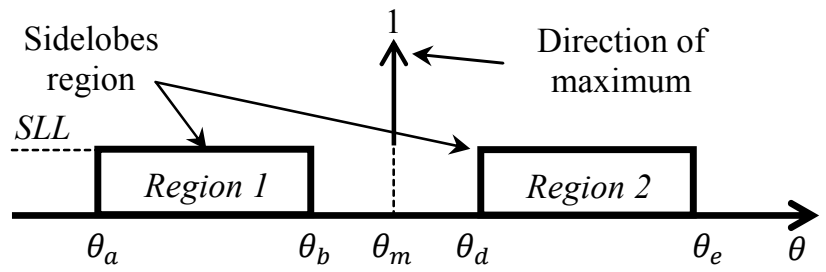

Fig. 2 - Mask for used for the synthesis for the switched-beam array. 


\section{DESIGN OF A HIGH-GAIN RECTANGULAR PATCH ANTENNA}

A rectangular patch antenna was designed to operate at the frequency allocated for wireless systems $(2.4 \mathrm{GHz})$. The structure is illustrated in Fig. 3. In this design, only FR4 laminates were used, in order to obtain a low-cost solution. A 2-mm thick air layer was inserted between the top FR4 laminate and the ground aiming to reduce the overall loss tangent of the structure, hence increasing radiation efficiency.

The FR4 laminate has the following characteristics: thickness $\left(h_{F R 4}\right)$ of $1.55 \mathrm{~mm}$, dielectric constant of 4.1 and dielectric loss tangent of 0.02 . The dimension $y_{0}$ is used to adjust the input impedance of the antenna. The width of microstrip feed $\left(W_{c}\right)$ was set to $10.5 \mathrm{~mm}$ so as to result in characteristic impedance equivalent to $50 \Omega$.

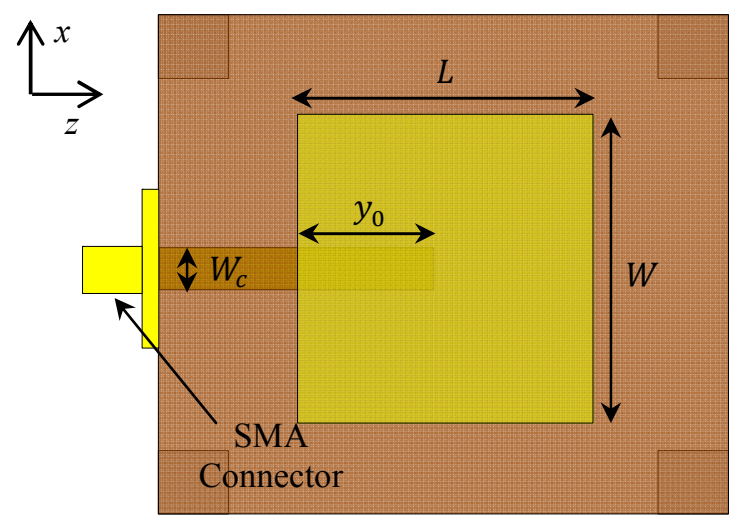

(a)

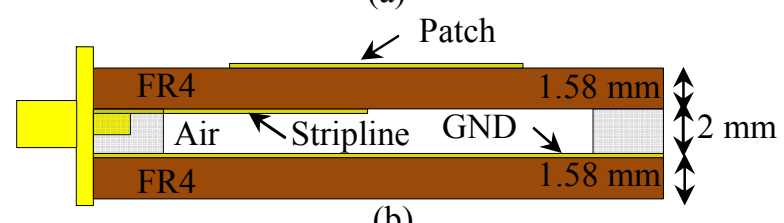

(b)

Fig. 3 - Microstrip antenna: (a) Top view; (b) Cross sectional view.

The antenna has been optimized using ANSYS HFSS software and the following dimensions were finally obtained: $W=70 \mathrm{~mm}, L=44.55 \mathrm{~mm}$, and $y_{0}=23 \mathrm{~mm}$. The antenna was fabricated and the photos of the prototype are shown in Fig 4. The simulated and measured radiation patterns are shown in Fig. 5 and Fig. 6.
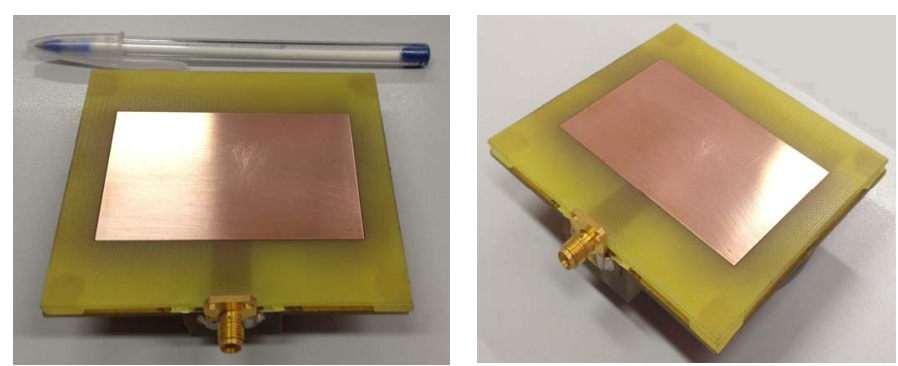

Fig. 4 - Fabricated prototype.
In Fig. 7, the simulated and measured results for the reflection coefficient are plotted. Very good agreement between the results is verified. By considering acceptable operation for reflection coefficient values lower than $-10 \mathrm{~dB}$, the antenna bandwidth is 2.34 to $2.46 \mathrm{GHz}$.

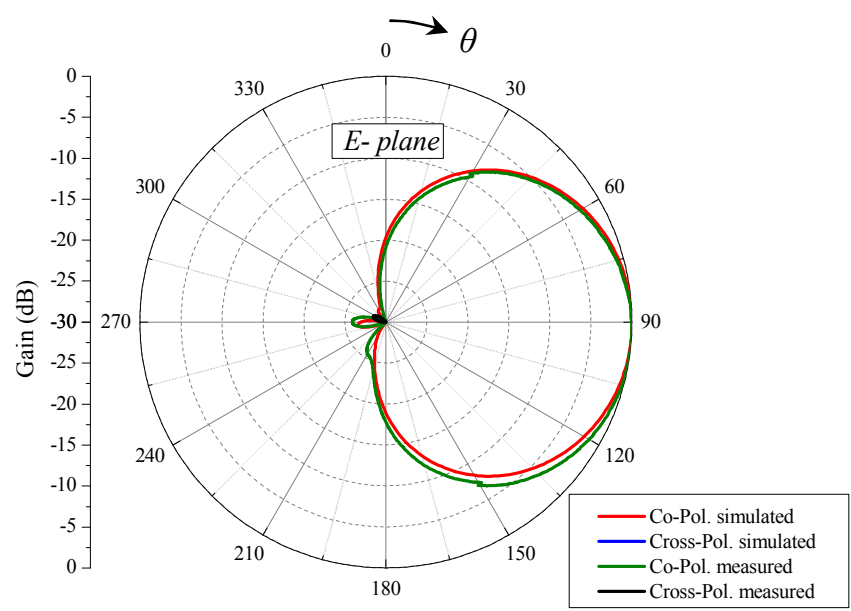

Fig. 5 - Radiation pattern in the $y z$-plane (azimuth plane).

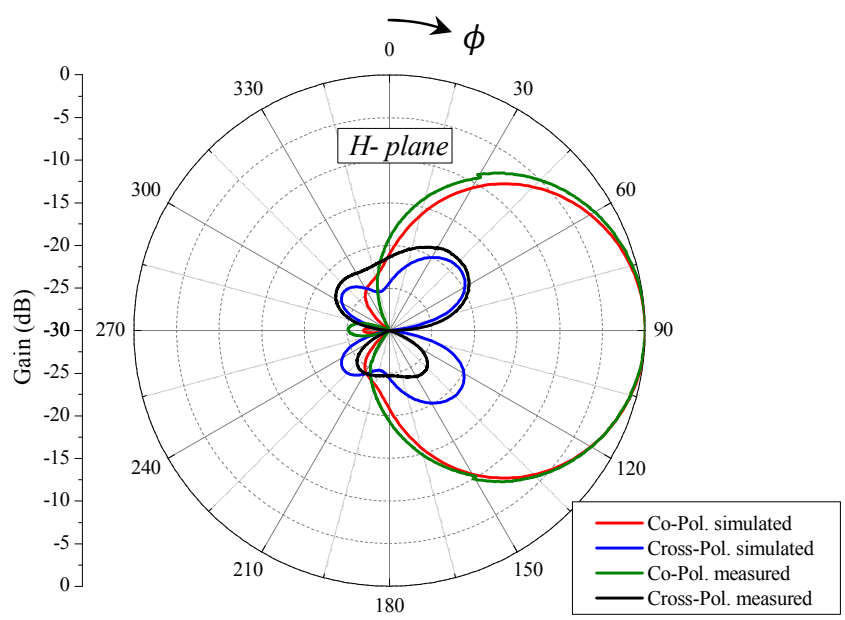

Fig. 6 - Radiation pattern in the $x z$-plane (elevation plane).

\section{SYNTHESIS OF AN 8-ELEMENT ARRAY}

In this study, a linear array of 8 elements uniformly spaced $\left(0.5 \lambda_{0}\right)$ along the horizontal direction is considered (see Fig. 1). In order to be employed for communication purposes, the array should be able to follow a mobile user by proper beam steering in the azimuth plane. In contrast to fully digital beamforming approach, the antenna under analysis should work as a switched beam array, hence only a discrete number of beams will be considered. Switching to another beam will happen as soon as the mobile user goes to a direction outside the angular region comprised in the HPBW of the beam in use. 


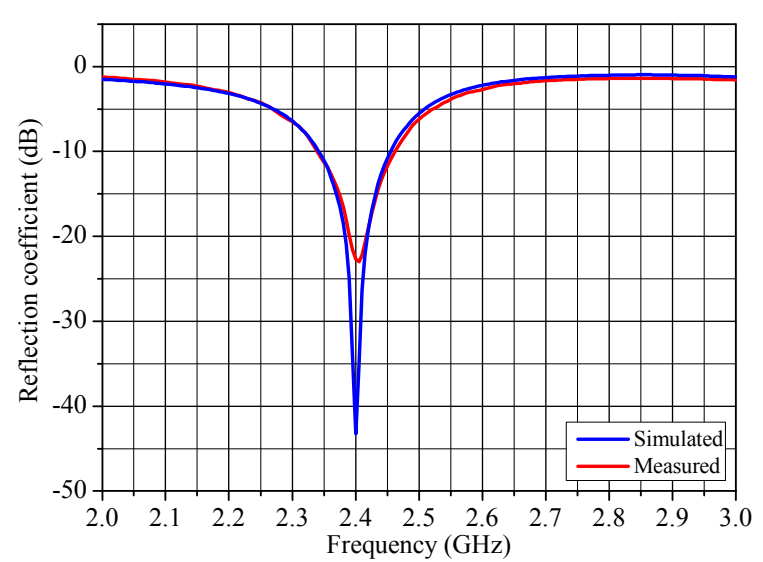

Fig. 7 - Reflection coefficient in the input antenna.

Initially, the array was assumed to be composed of ideally isotropic elements. The GA was initialized with a population of 70 individuals, with crossover probability of $85 \%$, mutation of $8 \%$, and $7 \%$ of individuals treated as elite. The limits of variation of the genes were set to $[0,1]$ for the amplitude and $[-\pi, \pi]$ for the phase. The linear arrays with isotropic elements were optimized over 250 generations with the GA, followed by the SQP started with the best individual. The sidelobe regions were defined approximately between $\left[0^{\circ}, \theta_{m}-15^{\circ}\right]$, $\left[\theta_{m}+15^{\circ}, 180^{\circ}\right]$, with maximum allowed SLL $20 \mathrm{~dB}$ below the level of the main beam. The steering directions $\left(\theta_{m}\right)$ were defined to be $60^{\circ}, 75^{\circ}, 90^{\circ}, 105^{\circ}$ and $120^{\circ}$. These values were chosen so as to obtain gain variations lower than $3 \mathrm{~dB}$ when switching over between two adjacent beams.

The results are shown in Fig. 8. The coefficients found when applying the synthesis algorithm for each beam are shown in Table I.

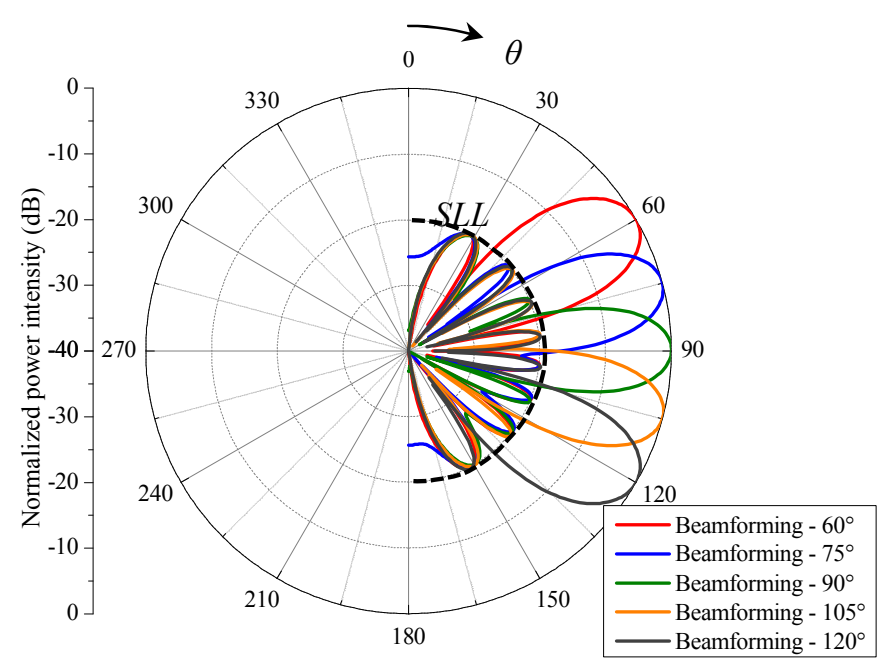

Fig. 8 - Switched-beam synthesized to isotropic antenna array.
In order to demonstrate the influence of the element radiation characteristic on the synthesized pattern to $\theta_{m}=60^{\circ}$, the isotropic elements were replaced by microstrip antennas. The obtained result can be viewed in Fig. 9. The radiation pattern does not satisfy anymore the specifications.

Subsequently, the radiation pattern of the microstrip element (see Fig. 5) was inserted in the synthesis process, resulting in the geometry shown in Fig. 10. The values for $\theta_{m}$ were the same as for the previous analysis, resulting in the beams shown in Fig. 11. The excitation coefficients for beams are shown in Table II.

Table I - Sets of coefficients synthesized for the isotropic antenna array.

\begin{tabular}{|c|c|c|c|c|c|}
\hline Ant. & $\begin{array}{c}\text { Coeffic.t } \\
\text { o } 60^{\circ}\end{array}$ & $\begin{array}{c}\text { Coeffic. } \\
\text { to } 75^{\circ}\end{array}$ & $\begin{array}{c}\text { Coeffic. } \\
\text { to } 90^{\circ}\end{array}$ & $\begin{array}{c}\text { Coeffic. } \\
\text { to } 105^{\circ}\end{array}$ & $\begin{array}{c}\text { Coeffic. } \\
\text { to } 120^{\circ}\end{array}$ \\
\hline 1 & $\begin{array}{c}0.339 \angle \\
137.3^{\circ}\end{array}$ & $\begin{array}{c}0.261 \angle \\
-104.9^{\circ}\end{array}$ & $\begin{array}{c}0.325 \angle \\
-1.4^{\circ}\end{array}$ & $\begin{array}{c}0.342 \angle \\
19.4^{\circ}\end{array}$ & $\begin{array}{c}0.348 \angle \\
-137.3^{\circ}\end{array}$ \\
\hline 2 & $0.439 \angle$ & $0.334 \angle$ & $0.405 \angle$ & $0.441 \angle$ & $0.443 \angle$ \\
& $46.7^{\circ}$ & $-148^{\circ}$ & $5.2^{\circ}$ & $65.4^{\circ}$ & $-46.6^{\circ}$ \\
\hline 3 & $0.766 \angle$ & $0.64 \angle$ & $0.725 \angle$ & $0.768 \angle$ & $0.77 \angle$ \\
& $-43.9^{\circ}$ & $149.2^{\circ}$ & $-2.3^{\circ}$ & $111.3^{\circ}$ & $44^{\circ}$ \\
\hline 4 & $1 \angle$ & $0.862 \angle$ & $0.96 \angle$ & $1 \angle$ & $1 \angle 2$ \\
& $-134.6^{\circ}$ & $107.5^{\circ}$ & $4.38^{\circ}$ & $157^{\circ}$ & $134.6^{\circ}$ \\
\hline 5 & $0.999 \angle$ & $1 \angle$ & $1 \angle$ & $0.999 \angle$ & $0.999 \angle$ \\
& $134.6^{\circ}$ & $60.6^{\circ}$ & $2.8^{\circ}$ & $-157^{\circ}$ & $-134.6^{\circ}$ \\
\hline 6 & $0.768 \angle$ & $0.796 \angle$ & $0.749 \angle$ & $0.77 \angle$ & $0.77 \angle$ \\
& $44^{\circ}$ & $9.5^{\circ}$ & $-4.6^{\circ}$ & $-111.3^{\circ}$ & $-44^{\circ}$ \\
\hline 7 & $0.437 \angle$ & $0.463 \angle$ & $0.458 \angle$ & $0.442 \angle$ & $0.444 \angle$ \\
& $-46.6^{\circ}$ & $-25.7^{\circ}$ & $1^{\circ}$ & $-65.4^{\circ}$ & $46.7^{\circ}$ \\
\hline 8 & $0.341 \angle$ & $0.303 \angle$ & $0.291 \angle$ & $0.345 \angle$ & $0.349 \angle$ \\
& $-137.3^{\circ}$ & $-78^{\circ}$ & $-6.8^{\circ}$ & $-19.6^{\circ}$ & $137.4^{\circ}$ \\
\hline & & & & & \\
\hline
\end{tabular}

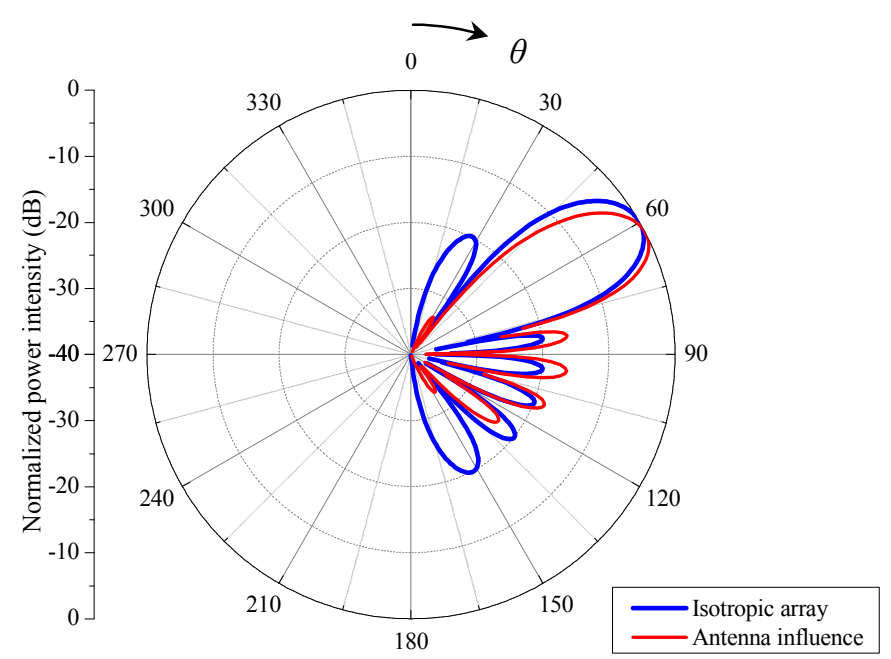

Fig. 9 - Influence of microstrip antenna on the synthesized radiation pattern to isotropic elements. 


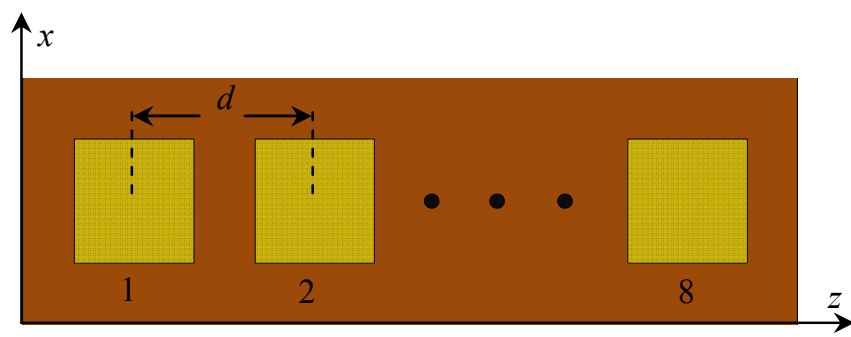

Fig. 10 - Geometry of a linear array of 8 microstrip antennas.

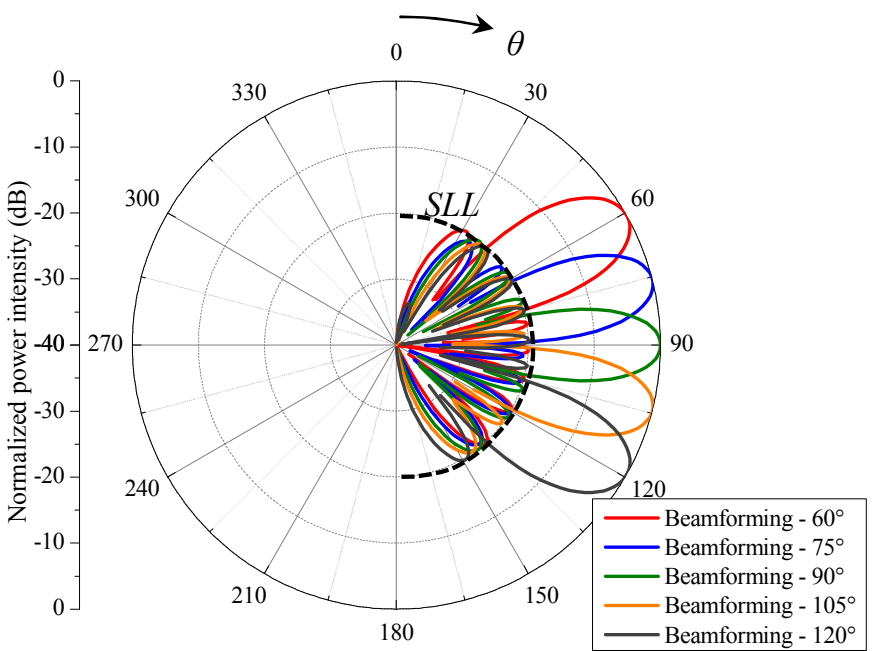

Fig. 11 - Switched-beam synthesized to microstrip antenna array.

Table II - Sets of coefficients synthesized for the microstrip antenna array.

\begin{tabular}{|c|c|c|c|c|c|}
\hline Ant. & $\begin{array}{c}\text { Coeffic. } \\
\text { to } 60^{\circ}\end{array}$ & $\begin{array}{c}\text { Coeffic. } \\
\text { to } 75^{\circ}\end{array}$ & $\begin{array}{c}\text { Coeffic. } \\
\text { to } 90^{\circ}\end{array}$ & $\begin{array}{l}\text { Coeffic. } \\
\text { to } 105^{\circ}\end{array}$ & $\begin{array}{l}\text { Coeffic. } \\
\text { to } 120^{\circ}\end{array}$ \\
\hline 1 & $\begin{array}{l}0.486 \angle \\
138.4^{\circ}\end{array}$ & $\begin{array}{l}0.87 \angle \\
-65.2^{\circ}\end{array}$ & $\begin{array}{l}0.99 \angle \\
-32.6^{\circ}\end{array}$ & $\begin{array}{l}0.642 \angle \\
-62.2^{\circ}\end{array}$ & $\begin{array}{l}0.462 \angle \\
-140.4^{\circ}\end{array}$ \\
\hline 2 & $\begin{array}{l}1 \angle \\
5^{\circ}\end{array}$ & $\begin{array}{l}0.527 \angle \\
-173.4^{\circ}\end{array}$ & $\begin{array}{l}0.009 \angle \\
-14.6^{\circ}\end{array}$ & $\begin{array}{c}0.555 \angle \\
39.5^{\circ}\end{array}$ & $\begin{array}{c}0.999 \angle \\
-8.4^{\circ}\end{array}$ \\
\hline 3 & $\begin{array}{c}0.73 \angle \\
-102.6^{\circ}\end{array}$ & $\begin{array}{c}0.41 \angle \\
-156.3^{\circ}\end{array}$ & $\begin{array}{c}1 \angle \\
-33.5^{\circ}\end{array}$ & $\begin{array}{c}0.186 \angle \\
57.5^{\circ}\end{array}$ & $\begin{array}{c}0.792 \angle \\
100.5^{\circ}\end{array}$ \\
\hline 4 & $\begin{array}{c}0.568 \angle \\
176^{\circ}\end{array}$ & $\begin{array}{c}1 \angle \\
133.5^{\circ}\end{array}$ & $\begin{array}{l}0.456 \angle \\
-28.5^{\circ}\end{array}$ & $\begin{array}{c}0.597 \angle \\
93.1^{\circ}\end{array}$ & $\begin{array}{l}0.536 \angle \\
-174.7^{\circ}\end{array}$ \\
\hline 5 & $\begin{array}{c}0.593 \angle \\
94^{\circ}\end{array}$ & $\begin{array}{c}0.838 \angle \\
81.9^{\circ}\end{array}$ & $\begin{array}{l}0.456 \angle \\
-34.4^{\circ}\end{array}$ & $\begin{array}{c}1 \angle \\
150.5^{\circ}\end{array}$ & $\begin{array}{c}0.533 \angle \\
-98.3^{\circ}\end{array}$ \\
\hline 6 & $\begin{array}{c}0.737 \angle \\
10.7^{\circ}\end{array}$ & $\begin{array}{c}0.408 \angle \\
27^{\circ}\end{array}$ & $\begin{array}{c}1 \angle \\
-29.4^{\circ}\end{array}$ & $\begin{array}{l}0.45 \angle \\
-132^{\circ}\end{array}$ & $\begin{array}{c}0.792 \angle \\
-13.7^{\circ}\end{array}$ \\
\hline 7 & $\begin{array}{l}0.995 \angle \\
-93.8^{\circ}\end{array}$ & $\begin{array}{c}0.409 \angle \\
25^{\circ}\end{array}$ & $\begin{array}{c}0.009 \angle \\
-48.4^{\circ}\end{array}$ & $\begin{array}{l}0.307 \angle \\
-158.2^{\circ}\end{array}$ & $\begin{array}{c}1 \angle \\
95.4^{\circ}\end{array}$ \\
\hline 8 & $\begin{array}{l}0.513 \angle \\
133.9^{\circ}\end{array}$ & $\begin{array}{c}0.791 \angle \\
-73.5^{\circ}\end{array}$ & $\begin{array}{l}0.99 \angle \\
-30.4^{\circ}\end{array}$ & $\begin{array}{c}0.695 \angle \\
-49.8^{\circ}\end{array}$ & $\begin{array}{l}0.461 \angle \\
-132.5^{\circ}\end{array}$ \\
\hline
\end{tabular}

\section{CONCLUSION}

The excitation coefficients synthesized with GA and SQP produce radiation patterns adequate for providing coverage with a ripple lower than $3 \mathrm{~dB}$ between adjacent beams and $S L L$ lower than $20 \mathrm{~dB}$. The currents obtained can be used in a switched-beam array that can be suitable for base stations of mobile communication systems. The combination of optimization methods allows synthesizing antenna arrays quickly. The obtained coefficients can be stored in a FPGA to be used as a look-up table, hence reducing the processing time for beam steering in comparison to fully digital beamforming architectures. The approach presented in this paper showed to be efficient and can be used for the synthesis of other shapes of radiation pattern as well.

\section{REFERENCES}

[1] K. F. Lee and K. M. Luk, Microstrip Patch Antennas, $1^{a}$ Ed. Imperial College Press, 2010.

[2] D.C.M. Maciel and J.C. da S. Lacava, "Circularly Polarized Planar Microstrip Phased Array With a Prescribed Beam Pattern Response," SBMO/IEEE MTT-S International Conference on Microwave and Optoelectronics, pp. 241-244, Jul. 2005.

[3] E. R. Schlosser, M. V. T. Heckler, M. Sperandio, and R. Machado, "Synthesis of Linear Antenna Arrays for Radio Base Stations," IEEE Antennas Propagation Society International Symposium, Orlando, USA, Jul. 2013.

[4] C. A. Balanis, Antenna Theory - Analysis and Design, $3^{\text {a }}$ Ed. John Wiley \& Sons, 2005.

[5] J. M. Johnson and Y. Rahmat-Samii, "Genetic Algorithm Optimization and its Application to Antenna Design," IEEE Antennas and Propagation Society International Symposium, vol.1, pp. 326-329, Aug. 1994.

[6] S. Koziel and S.Ogurtsov, "Linear antenna array synthesis using gradient-based optimization with analytical derivatives," IEEE Antennas Propagation Society International Symposium, Chicago, USA, Jul. 2012.

[7] E. R. Schlosser, M. V. T. Heckler, C. Lucatel, M. Sperandio, and R. Machado, "Synthesis of linear antenna array for $4 \mathrm{G}$ mobile communication systems," SBMO/IEEE MTTS International Microwave and Optoelectronics Conference (IMOC), Rio de Janeiro, Brazil, Aug. 2013.

[8] E. Siachalou, E. Vafiadis, S. S. Goudos, T.Samaras, C. S. Koukourlis, and S. Panas, "On The Design of Switched-Beam Wideband Base Stations," IEEE Antennas and Propagation Magazine, vol. 46, $\mathrm{n}^{\circ} 1$, Feb. 2004.

[9] W. C. Y. Lee, "Elements of Cellular Mobile Radio Systems," IEEE Trans. on Vehic. Tech., vol. VT-35, pp. 48-56, 1986.

[10] T. S. Rappaport, Wireless Communications: Principles and Practice, 2nd ed., vol.01. Prentice Hall, 2001, pp. 25-41. 